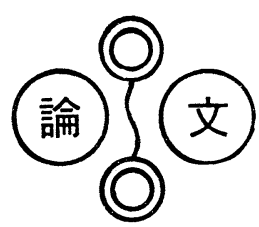

\title{
燃焼排ガス中の $\mathrm{NO}$ の酸化反応 (II) $-\mathrm{H}_{2}, \mathrm{H}_{2} \mathrm{O}_{2}, \mathrm{HCHO}, \mathrm{CH}_{4}$ 添加の效果一 \\ -1981. 12. 24 受理一
}

三菱重工業株式会社 村上 信明, 泉 順, 白川 精一

\section{1. はじめに}

燃燒排ガス中に含まれる数十ないし数百 $\mathrm{ppm}$ 程度 の希薄な酸化窒素 (NO) の二酸化窒素 $\left(\mathrm{NO}_{2}\right)$ への酸 化法ないし，その反応機構の検討は実用上は拈もに湿 式排煙処理法への適用 (一般にNOのままでは吸収・ 吸着除去は困難とされている）に関して重要であり， 化学反応的には現在迄に相当量堛積された $\mathrm{NO}_{x}$ の化 学の, 特に中温度域 $\left(300 \sim 1,000^{\circ} \mathrm{C}\right)$ 部分を補充する ものとして意義あるものと思われる。前報1)では酸素 $\left(\mathrm{O}_{2}\right)$ 共存下での $\mathrm{CH}_{3} \mathrm{OH}$ と $\mathrm{NO}$ の反応について述べ
た。

本報では過酸化水素 $\left(\mathrm{H}_{2} \mathrm{O}_{2}\right)$, ホルムアルデヒド $(\mathrm{HCHO})$, 水素 $\left(\mathrm{H}_{2}\right)$, メタン $\left(\mathrm{CH}_{4}\right)$ (以下添加剂と 呼ぶ）を用いた場合の各反応について記述する。

前報で述べたごとく，特に然焼排ガス中のような希 溥な濃度の NO を対象とし, 特定化学種存在下での $\mathrm{NO}_{2}$ の生成に着目した報告は, 炭化水素の燃燒過程 での $\mathrm{NO}_{2}$ 生成 ${ }^{2)}$,るいは, サンプリングプローブ 中での $\mathrm{NO}$ から $\mathrm{NO}_{2}$ への変換3などに関する文献を 除けば近時の特許報告 ${ }^{4}$ 以散見されるのみである。

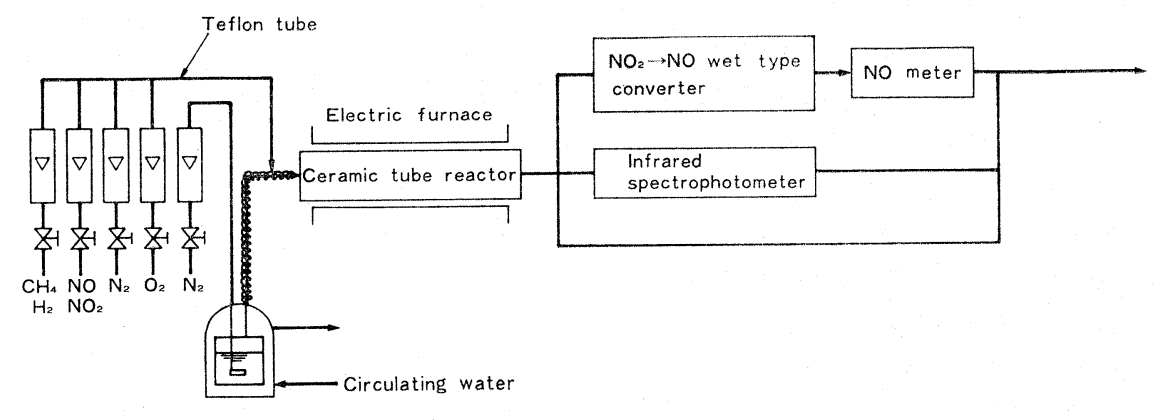

$\mathrm{H}_{2} \mathrm{O}_{2}$ or $\mathrm{HCHO}$ aq.

Fig. 1 Schematic diagram of the experimental system

\section{2. 試験装置および方法}

試験装置(Fig. 1) 执よび試験方法は概略前報と同様 であり, 電気师, 小型の管型反応器, 合成ガス流路を 主要構成要素とする流通式反応装置によって各添加剤 による $\mathrm{NO}$ の $\mathrm{NO}_{2}$ への酸化反応試験, 特よび $\mathrm{NO}_{2}$ $\left(\mathrm{O}_{2}\right)-\mathrm{N}_{2}$ 系での $\mathrm{NO}_{2}$ の $\mathrm{NO}$ への分解反応試験を実施 した。ただし, 反応器には前報と異なり, 磁性反応管 (内径 $24 \mathrm{~mm})$ を用い, 供試ガス $\left(\mathrm{N}_{2}\right.$ ベース, 全量は $3 \mathrm{~N} 1 /$ 分で一定とした）は所定濃度に調整したのち予 混合して流れ力向にFig. 2 に示すような温度分布をも つ反応器内に尊いた。Fig. 2 で均一温度域を $15 \mathrm{~cm}$ し てこれを単純に反灾域と考光れば反応時間は $600^{\circ} \mathrm{C} に$

長崎研究所化学研究室 長崎市飽の浦町1-1 特いて0.40sec. である。各ガス成分は, $\mathrm{NO}, \mathrm{O}_{2}, \mathrm{CH}_{4}$, $\mathrm{H}_{2}, \mathrm{NO}_{2}, \mathrm{~N}_{2}$ については市販の標準ガスボンべを使用

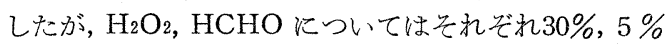
の過酸化水素水, パラホルムアルデヒド水溶液を容量 $200 \operatorname{cc}$ のエンケ氏式洗気ビンに満たし，その外側を 循環する恒温水で一定温度に保持して, 洗気ビン内に $\mathrm{N}_{2}$ ガスを通気し，その蒸気压に相当する量を得て， 他のガスと共に反応器に投入する方法によった。そし て, 供給ガス中の $\mathrm{H}_{2} \mathrm{O}_{2}$ 蒸気, $\mathrm{HCHO}$ 蒸気の濃度は, これらを別途蒸留水に吸収したのち，それぞれ，KMn $\mathrm{O}_{4}$ 滴定法, $\mathrm{Na}_{2} \mathrm{SO}_{3}$ 滴定法により求めるとともに，同 一の滴定法によって試験前後の洗気ビン中の水溶液濃 度に変化がないことを確認した。NOは化学発光式の 


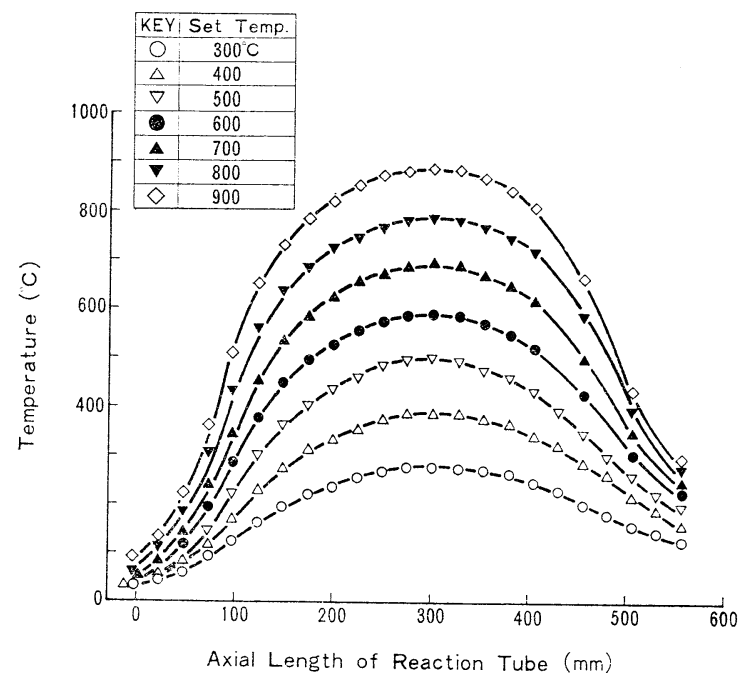

Fig. 2 Temperature profile

連続計測器 ((株)柳本製作所製 ECL-77A 型), $\mathrm{NO} x$ $\left(\mathrm{NO}+\mathrm{NO}_{2}\right)$ は湿式の $\mathrm{NO}_{2} \rightarrow \mathrm{NO}$ 転換法 (KI10wt $\%$ $+\mathrm{H}_{2} \mathrm{SO}_{4} 10 \mathrm{wt} \%$ 水溶液に供試ガスを通気することに より，含有 $\mathrm{NO}_{2}$ は活とんど $100 \% \mathrm{NO}$ に変換される ことを利用した。本方法の妥当性は $\mathrm{NO}_{2}$ の標準ボン ベガスを用いて確認した）により連続分析するととも K，適宜赤外分光光度計 ((株)島津製作所製, IR-430 型)によって $\mathrm{NO}_{2}$ 生成の確認などを行った。反応ガ ス中の $\mathrm{NO}_{2}$ 濃度は $\left[\mathrm{NO}_{2}\right]=\left[\mathrm{NO}_{x}\right]-[\mathrm{NO}]([]$ は濃度 $(\mathrm{ppm})$ を示す) として求めた。また, $\mathrm{H}_{2}, \mathrm{CH}_{4}$, $\mathrm{CO}$ 濃度の分析には TCD 方式のガスクロマトグラフ ((株)島津製作所製，GC-3BT 型）を用いた。

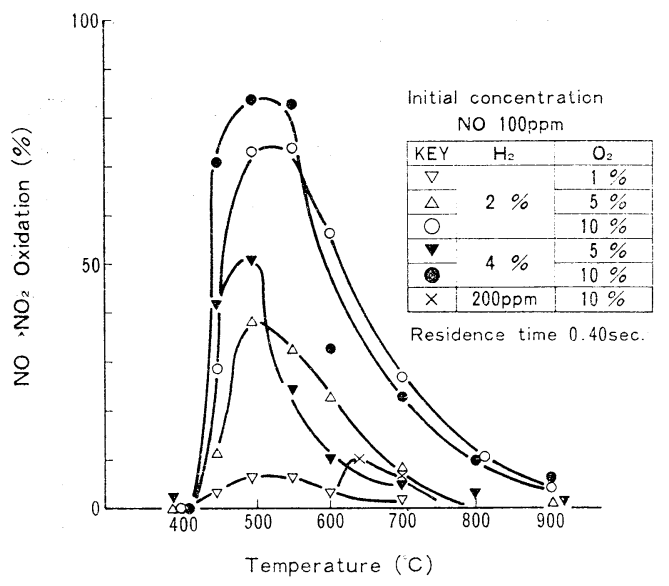

Fig. 3 NO oxidation by addition of $\mathbf{H}_{2}$

\section{3. 試 験 結 果}

各添加剂を用いた場合の試験結果をFig.3〜 6 に，また，本試験装置での $\mathrm{NO}_{2}$ の分解特性を Fig. 7 に示す。(Fig. 3 ) $\mathrm{H}_{2}$, (Fig. 4 ) $\mathrm{H}_{2} \mathrm{O}_{2}$, (Fig. 5 ) $\mathrm{HCHO}$, (Fig. 6) $\mathrm{CH}_{4}$

$\mathrm{H}_{2}, \mathrm{H}_{2} \mathrm{O}_{2}, \mathrm{HCHO}$ の場合は, 反応前の $\mathrm{NO}$ 值と反応後の $\mathrm{NO}_{x}\left(\mathrm{NO}+\mathrm{NO}_{2}\right)$ 值は同一であ り, 従って減少した $\mathrm{NO}$ はすべて $\mathrm{NO}_{2}$ に酸 化されたものと思われるが， $\mathrm{CH}_{4}$ の場合には 反応後の $\mathrm{NO}_{x}$ 值は反応前の $\mathrm{NO}$ 值より低く, その差分は $\mathrm{NO}_{2}$ とは別の形の窒素化合物 $\left(\mathrm{N}_{2}\right.$ など）に転換されたものと思われる。Fig. 6 中 には NO 残留率 (上図) も併せ示している。

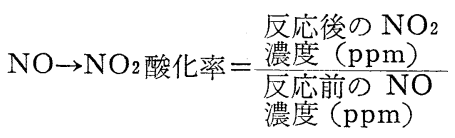$$
\times 100(\%)
$$

$\mathrm{NO}$ 残留率 $=\frac{\text { 反応後の } \mathrm{NO} \text { 濃度 }(\mathrm{ppm})}{\text { 反応前の } \mathrm{NO} \text { 濃度 }(\mathrm{ppm})}$

$$
\times 100(\%)
$$

$\mathrm{CH}_{4}$ 以外の場合には上記(1)と(2)の値は(1)=100-(2) ％）の関係にある。

NOに対して酸化作用を有するこれらの化合物の反 㐫性を比較すると, $\mathrm{NO}_{2}$ 生成には, $\mathrm{CH}_{3} \mathrm{OH}$ (前報), $\mathrm{HCHO}, \mathrm{H}_{2} \mathrm{O}_{2}$ では注ぼ $\mathrm{NO}$ の等量モルの添加で充 分で京るのに比し， $\mathrm{CH}_{4}, \mathrm{H}_{2}$ では $\mathrm{NO}$ の数十倍モル 量の添加が必要である。また他の添加剤と異なり, $\mathrm{H}_{2} \mathrm{O}_{2}$ のみは $\mathrm{O}_{2}$ の共存がなくとも $\mathrm{NO}$ に対して酸化

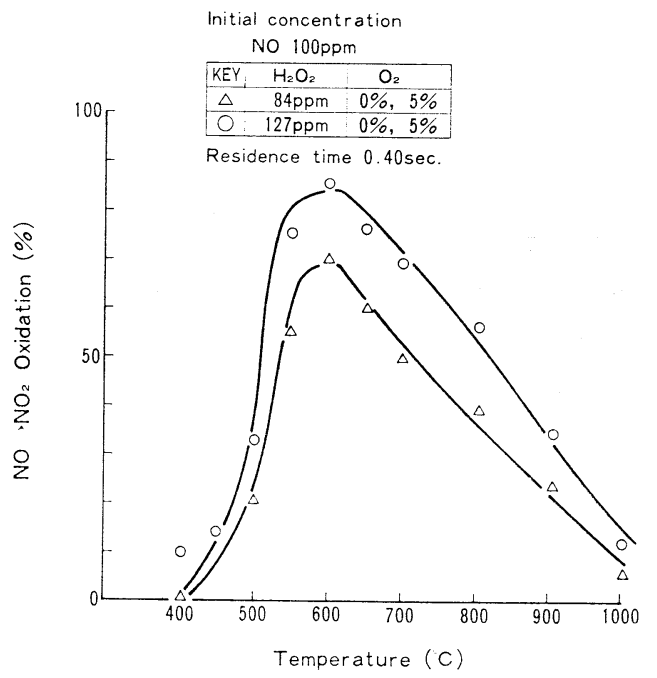

Fig. 4 NO oxidation by addition of $\mathrm{H}_{2} \mathrm{O}_{2}$ 

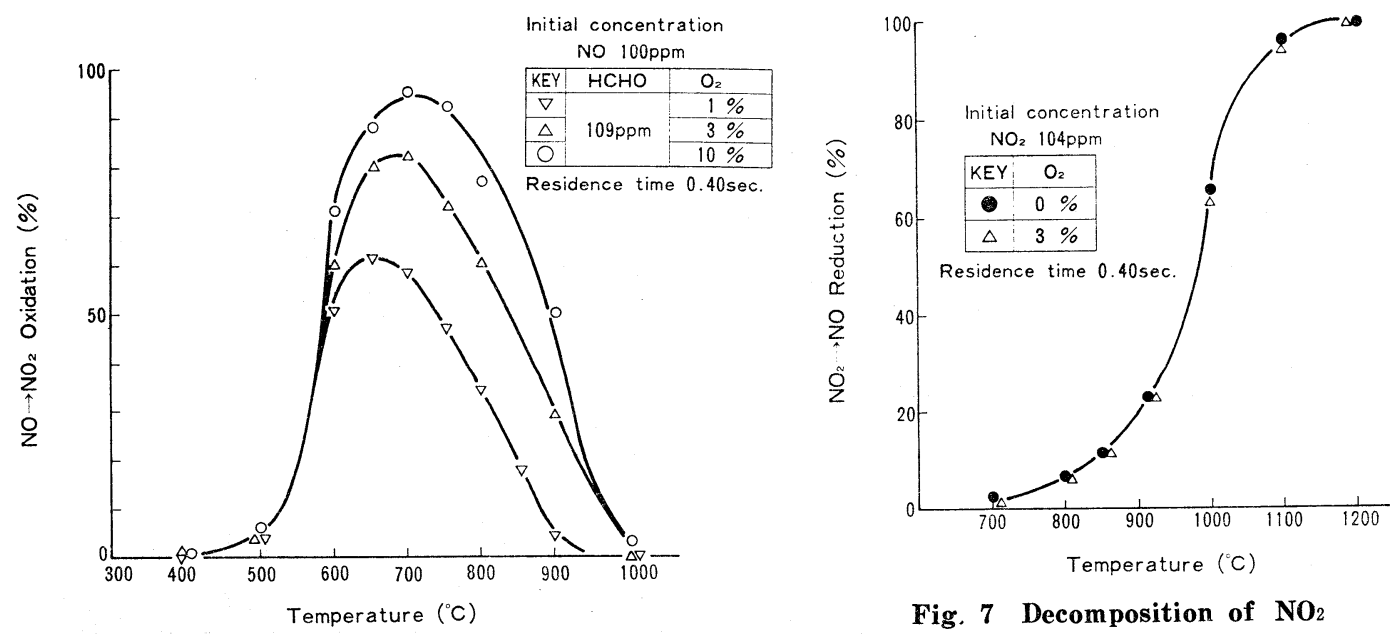

Fig. 5 NO oxidation by addition of HCHO

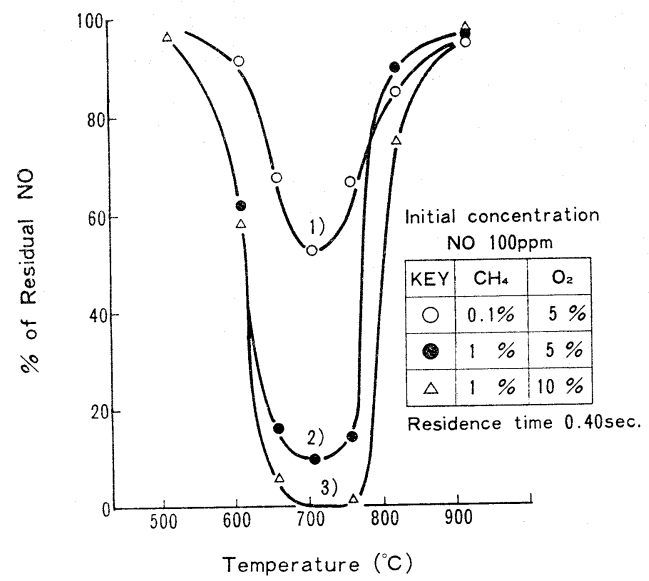
たく関係しない。

このように希薄濃度の NOは酸素存在下 $300 \sim 1,000$ ${ }^{\circ} \mathrm{C}$ では非常に反応性に富んだ化学種であり, その場合 には多く $\mathrm{NO}_{2}$ の形で関与していることが理解される。 そして低温度 ( $350^{\circ} \mathrm{C}$ 以下) では $\mathrm{H}_{2}, \mathrm{HCHO}, \mathrm{CH}_{4}$ な ぞの $\mathrm{O}_{2}$ による分解が生じないので $\mathrm{NO}_{2}$ も生成せず, 逆に高温度では $\mathrm{NO}_{2}$ はかなり容易に $\mathrm{NO}$ に再分解す るから, $\mathrm{NO}_{2}$ の生成には常に最適な温度域が存在す ることになる。そしてその最適温度域も涯加剤の種 類, 操作条件により微妙に異なってくる。ただ $\mathrm{NO}_{2}$ の反（または $\mathrm{O}_{2}$ の共存下で）の分解はFig. 7 からる 判るように $800^{\circ} \mathrm{C}$ 以下ではさして大きくないので，多 くの場合Hラジカルのような反応中間体が関与してい ると推定される。また， $\mathrm{H}_{2} \mathrm{O}_{2}$ の場合には $\mathrm{O}_{2}$ による 分解生成物ではなく, $\mathrm{H}_{2} \mathrm{O}_{2}$ そのものから生じる熱分

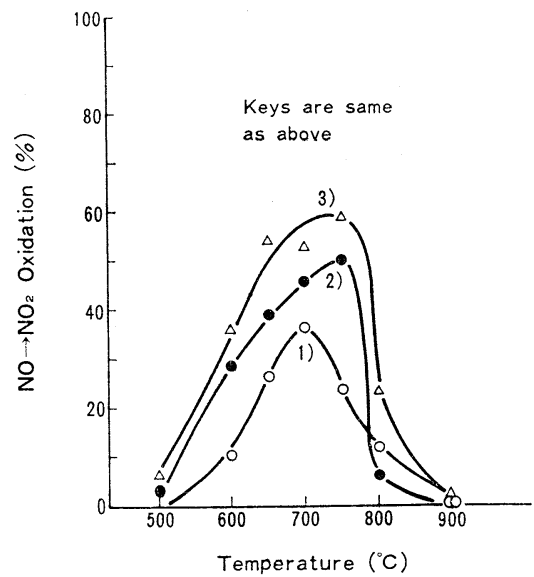

Fig. 6 NO oxidation by addition of $\mathrm{CH}_{4}$
解生成物が $\mathrm{NO}$ 亿作用し, $\mathrm{NO}_{2}$ を生成するのである う。

\section{4. 考察}

以上で前報1での $\mathrm{CH}_{3} \mathrm{OH}$ をも含め, 5 種の添加剤 $\left(\mathrm{H}_{2}, \mathrm{H}_{2} \mathrm{O}_{2}, \mathrm{HCHO}, \mathrm{CH}_{3} \mathrm{OH}, \mathrm{CH}_{4}\right)$ ¿ $\mathrm{NO}, \mathrm{O}_{2}$ と から $\mathrm{NO}_{2}$ を生成する反応についての知見が得られた。 ここでは前報で用いた $\mathrm{CH}_{4}, \mathrm{CH}_{3}, \mathrm{CH}_{2}, \mathrm{CH}, \mathrm{CHO}$, $\mathrm{CO}, \mathrm{CO}_{2}, \mathrm{H}, \mathrm{H}_{2}, \mathrm{H}_{2} \mathrm{O}$, $\mathrm{HCHO}$ (Table1 には $\mathrm{H}_{2} \mathrm{CO}$ と表記), $\mathrm{HO}_{2}, \mathrm{H}_{2} \mathrm{O}_{2}, \mathrm{O}_{2}, \mathrm{O}, \mathrm{OH}, \mathrm{N}_{2}, \mathrm{~N}, \mathrm{NO}, \mathrm{NO}_{2}$, $\mathrm{CH}_{3} \mathrm{OH}, \mathrm{CH}_{2} \mathrm{OH}$ の 22 種の化学種と, 70の素反応群 を考虑した反応モデルによって計算した結果を実験結 果と対比・考察する。前報でも述べたように, これら の素反応データの中には暫定的な值も多く, 本来使用 


\section{Table 1 Rate constant}

$\mathrm{k}_{\mathrm{f}}=\mathrm{AT}^{\mathrm{n}} \exp (-\mathrm{E} / \mathrm{RT})$ (rate const. of forward reaction), unit ; cm, mol, sec, ${ }^{\circ} \mathrm{K}$

\begin{tabular}{|c|c|c|c|c|c|}
\hline \multirow{2}{*}{ No } & \multirow{2}{*}{ Reaction } & \multicolumn{4}{|c|}{$k_{f}$} \\
\hline & & A & & $n$ & $E$ \\
\hline 1 & $\mathrm{CH}_{3} \mathrm{OH}+\mathrm{M}=\mathrm{CH}_{3}+\mathrm{OH}+\mathrm{M}$ & 3.16 & E18 & 0 & 80000 \\
\hline 2 & $\mathrm{CH}_{3} \mathrm{OH}+\mathrm{O}_{2}=\mathrm{CH}_{2} \mathrm{OH}+\mathrm{HO}_{2}$ & 4.00 & $\mathrm{E} 13$ & 0 & 50900 \\
\hline 3 & $\mathrm{CH}_{3} \mathrm{OH}+\mathrm{CH}_{3}=\mathrm{CH}_{2} \mathrm{OH}+\mathrm{CH}_{4}$ & 2.00 & E11 & 0 & 9800 \\
\hline 4 & $\mathrm{CH}_{3} \mathrm{OH}+\mathrm{O}=\mathrm{CH}_{2} \mathrm{OH}+\mathrm{OH}$ & 1.70 & E12 & 0 & 2280 \\
\hline 5 & $\mathrm{CH}_{3} \mathrm{OH}+\mathrm{H}=\mathrm{CH}_{3}+\mathrm{H}_{2} \mathrm{O}$ & 5.00 & E12 & 0 & 5300 \\
\hline 6 & $\mathrm{CH}_{3} \mathrm{OH}+\mathrm{H}=\mathrm{CH}_{2} \mathrm{OH}+\mathrm{H}_{2}$ & 3.16 & $E 13$ & 0 & 7000 \\
\hline 7 & $\mathrm{CH}_{3} \mathrm{OH}+\mathrm{OH}=\mathrm{CH}_{2} \mathrm{OH}+\mathrm{H}_{2} \mathrm{O}$ & 2.00 & $E 13$ & 0 & 2000 \\
\hline 8 & $\mathrm{CH}_{3} \mathrm{OH}+\mathrm{HO}_{2}=\mathrm{CH}_{2} \mathrm{OH}+\mathrm{H}_{2} \mathrm{O}_{2}$ & 6.31 & E12 & 0 & 19400 \\
\hline 9 & $\mathrm{CH}_{2} \mathrm{OH}+\mathrm{O}_{2}=\mathrm{CH}_{2} \mathrm{O}+\mathrm{HO}_{2}$ & 1.00 & E10 & 0 & 6000 \\
\hline 10 & $\mathrm{CH}_{2} \mathrm{OH}+\mathrm{M}=\mathrm{CH}_{2} \mathrm{O}+\mathrm{H}+\mathrm{M}$ & 12.5 & E13 & 0 & 29000 \\
\hline 11 & $\mathrm{CH}_{4}+\mathrm{M}=\mathrm{CH}_{3}+\mathrm{H}+\mathrm{M}$ & 1.0 & E17 & 0 & 88000 \\
\hline 12 & $\mathrm{CH}_{4}+\mathrm{O}=\mathrm{CH}_{3}+\mathrm{OH}$ & 2.1 & E13 & 0 & 9040 \\
\hline 13 & $\mathrm{CH}_{4}+\mathrm{OH}=\mathrm{CH}_{3}+\mathrm{H}_{2} \mathrm{O}$ & 2.8 & E13 & 0 & 4980 \\
\hline 14 & $\mathrm{CH}_{4}+\mathrm{H}=\mathrm{CH}_{3}+\mathrm{H}_{2}$ & 2.24 & E4 & 3.0 & 8750 \\
\hline 15 & $\mathrm{CH}_{3}+\mathrm{O}=\mathrm{H}_{2} \mathrm{CO}+\mathrm{H}$ & 6.4 & E13 & & \\
\hline 16 & $\mathrm{CH}_{3}+\mathrm{O}=\mathrm{CH}_{2}+\mathrm{OH}$ & 1.0 & $E 12$ & 0 & 10000 \\
\hline 17 & $\mathrm{CH}_{3}+\mathrm{OH}=\mathrm{H}_{2} \mathrm{CO}+\mathrm{H}_{2}$ & 4.0 & E12 & & \\
\hline 18 & $\mathrm{CH}_{3}+\mathrm{OH}=\mathrm{CH}_{2}+\mathrm{H}_{2} \mathrm{O}$ & 1.0 & E12 & 0 & 6000 \\
\hline 19 & $\mathrm{CH}_{3}+\mathrm{H}=\mathrm{CH}_{2}+\mathrm{H}_{2}$ & 1.0 & $E 13$ & 0 & 12000 \\
\hline 20 & $\mathrm{CH}_{3}+\mathrm{O}_{2}=\mathrm{H}_{2} \mathrm{CO}+\mathrm{OH}$ & 1.2 & E11 & 0 & 9940 \\
\hline 21 & $\mathrm{H}_{2} \mathrm{CO}+\mathrm{M}=\mathrm{CHO}+\mathrm{H}+\mathrm{M}$ & 5.01 & E16 & 0 & 92000 \\
\hline 22 & $\mathrm{H}_{2} \mathrm{CO}+\mathrm{O}=\mathrm{CHO}+\mathrm{OH}$ & 5.0 & E13 & 0 & 4600 \\
\hline 23 & $\mathrm{H}_{2} \mathrm{CO}+\mathrm{OH}=\mathrm{CHO}+\mathrm{H}_{2} \mathrm{O}$ & 2.9 & E13 & 0 & 740 \\
\hline 24 & $\mathrm{H}_{2} \mathrm{CO}+\mathrm{H}=\mathrm{CHO}+\mathrm{H}_{2}$ & 5.45 & E13 & 0 & 4470 \\
\hline 25 & $\mathrm{CH}_{2}+\mathrm{O}=\mathrm{CH}+\mathrm{OH}$ & 1.9 & E11 & 0.68 & 25700 \\
\hline 26 & $\mathrm{CH}_{2}+\mathrm{OH}=\mathrm{CH}+\mathrm{H}_{2} \mathrm{O}$ & 2.7 & E11 & 0.67 & 25700 \\
\hline 27 & $\mathrm{CH}_{2}+\mathrm{H}=\mathrm{CH}+\mathrm{H}_{2}$ & 2.7 & E11 & 0.67 & 25700 \\
\hline 28 & $\mathrm{CH}_{2}+\mathrm{O}_{2}=\mathrm{CHO}+\mathrm{OH}$ & 1.0 & $E 14$ & 0 & 3700 \\
\hline 29 & $\mathrm{CHO}+\mathrm{M}=\mathrm{CO}+\mathrm{H}+\mathrm{M}$ & 7.0 & E13 & 0 & 15000 \\
\hline 30 & $\mathrm{CHO}+\mathrm{O}=\mathrm{CO}+\mathrm{OH}$ & 1.0 & E14 & & \\
\hline 31 & $\mathrm{CHO}+\mathrm{OH}=\mathrm{CO}+\mathrm{H}_{2} \mathrm{O}$ & 3.0 & E13 & & \\
\hline 32 & $\mathrm{CHO}+\mathrm{H}=\mathrm{CO}+\mathrm{H}_{2}$ & 2.0 & E13 & & \\
\hline 33 & $\mathrm{CHO}+\mathrm{O}_{2}=\mathrm{CO}+\mathrm{HO}_{2}$ & 4.95 & E13 & 0 & 1590 \\
\hline 34 & $\mathrm{CH}+\mathrm{O}_{2}=\mathrm{CO}+\mathrm{OH}$ & 1.1 & E11 & 0.67 & 25700 \\
\hline 35 & $\mathrm{CH}+\mathrm{O}_{2}=\mathrm{CHO}+\mathrm{O}$ & 1.0 & E13 & & \\
\hline 36 & $\mathrm{CO}+\mathrm{OH}=\mathrm{CO}_{2}+\mathrm{H}$ & & & & \\
\hline 37 & $\mathrm{CO}+\mathrm{O}+\mathrm{M}=\mathrm{CO}_{2}+\mathrm{M}$ & 1.0 & E19 & -1.5 & 5000 \\
\hline 38 & $\mathrm{CO}+\mathrm{O}_{2}=\mathrm{CO}_{2}+\mathrm{O}$ & 8.84 & E11 & 0 & 43230 \\
\hline 39 & $\mathrm{H}_{2}+\mathrm{O}=\mathrm{OH}+\mathrm{H}$ & 1.8 & E10 & 1.0 & 8900 \\
\hline 40 & $\mathrm{H}_{2}+\mathrm{OH}=\mathrm{H}_{2} \mathrm{O}+\mathrm{H}$ & 2.19 & E13 & 0 & 5150 \\
\hline 41 & $\mathrm{H}+\mathrm{O}_{2}=\mathrm{OH}+\mathrm{O}$ & 2.24 & E14 & 0 & 16800 \\
\hline 42 & $\mathrm{H}+\mathrm{O}_{2}+\mathrm{M}=\mathrm{HO}_{2}+\mathrm{M}$ & 1.5 & E15 & 0 & 990 \\
\hline
\end{tabular}

\begin{tabular}{|c|c|c|c|c|c|}
\hline \multirow{2}{*}{ No } & \multirow{2}{*}{ Reaction } & \multicolumn{4}{|c|}{$k_{f}$} \\
\hline & & A & & $n$ & E \\
\hline 43 & $\mathrm{H}+\mathrm{OH}+\mathrm{M}=\mathrm{H}_{2} \mathrm{O}+\mathrm{M}$ & 1.54 & E19 & -0.9639 & 0 \\
\hline 44 & $\mathrm{O}+\mathrm{H}_{2} \mathrm{O}=\mathrm{OH}+\mathrm{OH}$ & 6.8 & E13 & 0 & 18360 \\
\hline 45 & $\mathrm{OH}+\mathrm{OH}=\mathrm{HO}_{2}+\mathrm{H}$ & 1.71 & E13 & 0 & 40460 \\
\hline 46 & $\mathrm{H}_{2}+\mathrm{M}=\mathrm{H}+\mathrm{H}+\mathrm{M}$ & 4.58 & E14 & 0 & 99880 \\
\hline 47 & $0_{2}+M=0+0+M$ & 1.78 & E18 & -1.0 & 117960 \\
\hline 48 & $\mathrm{H}+\mathrm{HO}_{2}=\mathrm{H}_{2}+\mathrm{O}_{2}$ & 2.5 & E13 & 0 & 695 \\
\hline 49 & $\mathrm{H}+\mathrm{HO}_{2}=\mathrm{H}_{2} \mathrm{O}+\mathrm{O}$ & 5.0 & E13 & 0 & 1000 \\
\hline 50 & $\mathrm{HO}_{2}+\mathrm{HO}_{2}=\mathrm{H}_{2} \mathrm{O}_{2}+\mathrm{O}_{2}$ & 1.8 & E13 & 0 & 990 \\
\hline 51 & $\mathrm{H}_{2} \mathrm{O}_{2}+\mathrm{OH}=\mathrm{H}_{2} \mathrm{O}+\mathrm{HO}_{2}$ & 1.0 & E13 & 0 & 1810 \\
\hline 52 & $\mathrm{H}_{2} \mathrm{O}_{2}+\mathrm{H}=\mathrm{H}_{2}+\mathrm{HO}_{2}$ & 1.7 & E12 & 0 & 3780 \\
\hline 53 & $\mathrm{H}_{2} \mathrm{O}_{2}+\mathrm{H}=\mathrm{H}_{2} \mathrm{O}+\mathrm{OH}$ & 2.2 & E15 & 0 & 11720 \\
\hline 54 & $\mathrm{H}_{2} \mathrm{O}_{2}+\mathrm{O}=\mathrm{HO}_{2}+\mathrm{OH}$ & 2.8 & E13 & 0 & 6360 \\
\hline 55 & $\mathrm{HO}_{2}+\mathrm{OH}=\mathrm{H}_{2} \mathrm{O}+\mathrm{O}_{2}$ & 5.0 & E13 & 0 & 1000 \\
\hline 56 & $\mathrm{HO}_{2}+\mathrm{O}=\mathrm{OH}+\mathrm{O}_{2}$ & 4.8 & E13 & 0 & 1000 \\
\hline 57 & $\mathrm{H}_{2} \mathrm{O}_{2}+\mathrm{M}=2 \mathrm{OH}+\mathrm{M}$ & 1.2 & E17 & 0 & 45500 \\
\hline 58 & $\mathrm{CH}_{3}+\mathrm{O}=\mathrm{CH}+\mathrm{H}_{2} \mathrm{O}$ & 1.0 & E14 & & \\
\hline 59 & $\mathrm{CH}_{3}+\mathrm{O}_{2}=\mathrm{CHO}+\mathrm{H}_{2} \mathrm{O}$ & 2.0 & E10 & & \\
\hline 60 & $\mathrm{CH}_{3}+\mathrm{O}=\mathrm{CHO}+\mathrm{H}_{2}$ & 1.0 & $E 14$ & & \\
\hline 61 & $\mathrm{CH}_{4}+\mathrm{O}_{2}=\mathrm{CH}_{3}+\mathrm{HO}_{2}$ & 1.0 & $E 14$ & 0 & 55000 \\
\hline 62 & $\mathrm{HO}_{2}+\mathrm{CO}=\mathrm{CO}_{2}+\mathrm{OH}$ & 1.0 & E11 & 0 & 9940 \\
\hline 63 & $\mathrm{NO}+\mathrm{N}=\mathrm{O}+\mathrm{N}_{2}$ & 1.55 & E13 & & \\
\hline 64 & $\mathrm{~N}+\mathrm{O}_{2}=\mathrm{NO}+\mathrm{O}$ & 9.81 & E9 & 1.0 & 6610 \\
\hline 65 & $\mathrm{~N}+\mathrm{OH}=\mathrm{NO}+\mathrm{H}$ & 4.2 & E13 & & \\
\hline 66 & $\mathrm{NO}_{2}+\mathrm{M}=\mathrm{NO}+\mathrm{O}+\mathrm{M}$ & 1.41 & E21 & -1.31 & 71860 \\
\hline 67 & $\mathrm{NO}_{2}+\mathrm{O}=\mathrm{NO}+\mathrm{O}_{2}$ & 7.65 & E12 & 0 & 430 \\
\hline 68 & $2 \mathrm{NO}+\mathrm{O}_{2}=\mathrm{NO}_{2}+\mathrm{NO}_{2}$ & 7.95 & E9 & & \\
\hline 69 & $\mathrm{NO}_{2}+\mathrm{H}=\mathrm{NO}+\mathrm{OH}$ & 3.50 & $E 14$ & 0 & 1470 \\
\hline 70 & $\mathrm{NO}+\mathrm{HO}_{2}=\mathrm{NO}_{2}+\mathrm{OH}$ & 3.02 & E12 & 0.5 & 2400 \\
\hline
\end{tabular}

$1.0 E 10=1.0 \times 10^{20}$ 
され得る温度域を超えて使用しているものもあり，従 って反応全体の正確な記述は現状では困難である。せ た，本試験のように温度分布，流速分布をもった反応 試験の解析に適用するのは問題もあるが，関係化学種 が多い系の反応機構を考察するには便利であり，本報 でもこの方法によることとし，各添加物での試験結果 を矛盾なく説明し得る反応モデルを検討した。計算 法, Table 1 中の 速度定数の引用文献は前報1) と同一 である。

Table 1 の素反応群，反応速度を用い，実験で採用 した条件と近い条件でのモデル計算結果を，各添加剤 の $\mathrm{NO} \rightarrow \mathrm{NO}_{2}$ 酸化作用につき，それぞれFig. $8 \sim 11$ に 示す。また, $\mathrm{NO}_{2}$ の分解特性についての計算結果を

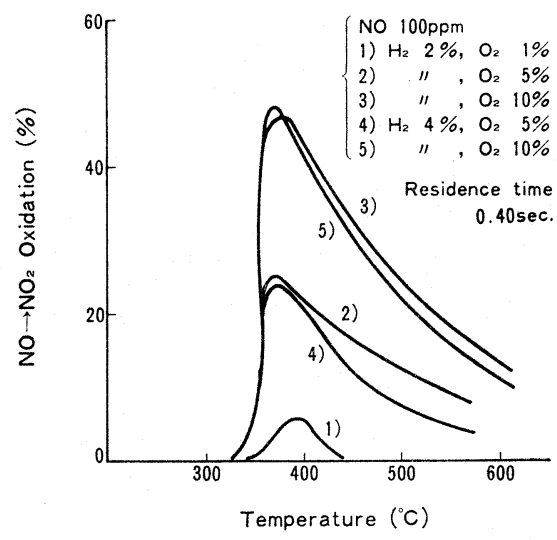

Fig. 8 NO oxidation at $\mathrm{H}_{2}-\mathrm{O}_{2}-\mathrm{NO}$ sys. (calculated)

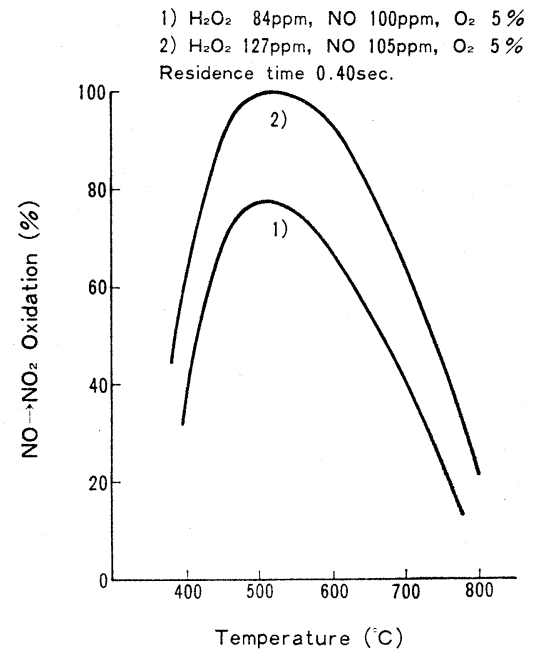

Fig. 9 NO oxidation at $\mathrm{H}_{2} \mathrm{O}_{2}-\mathrm{NO}-\mathrm{O}_{2}$ sys. (calculated)
Fig.12に示すが，いずれも実験結果と良く対応してい るように思われる。

Table 1の反応速度定数は以下の理由で選定したも のである。(k7, k9, k10 については前報参照)。

Table 1 の反応速度定数のうち，C を含まぬ系，す なわち, $\mathrm{H}_{2}-\mathrm{O}_{2}-\mathrm{NO}$ 系, $\mathrm{H}_{2} \mathrm{O}_{2}-\left(\mathrm{O}_{2}\right)-\mathrm{NO}$ 系の反応拈

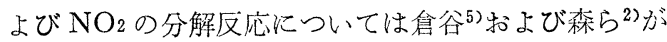
収集・整理した值を用いて試験結果とモデル計算結果 はほぼ満足すべき対応が得られた。しかし，Cを含も

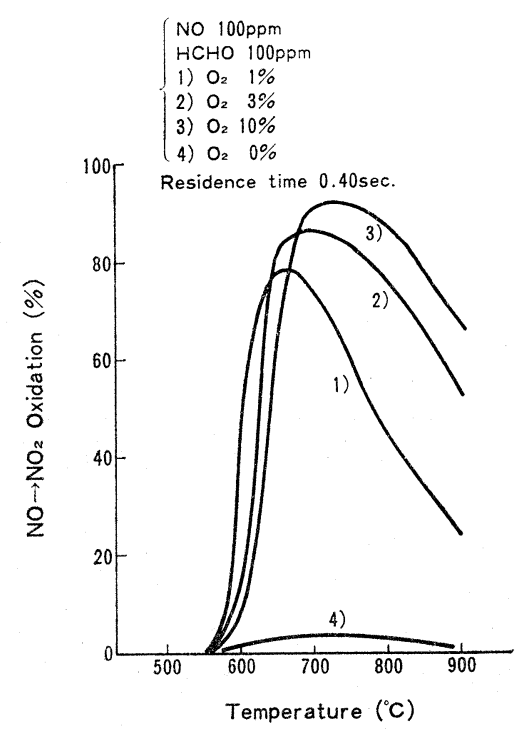

Fig. 10 NO oxidation at $\mathrm{HCHO}-\mathrm{O}_{2}-\mathrm{NO}$ sys. (calculated)

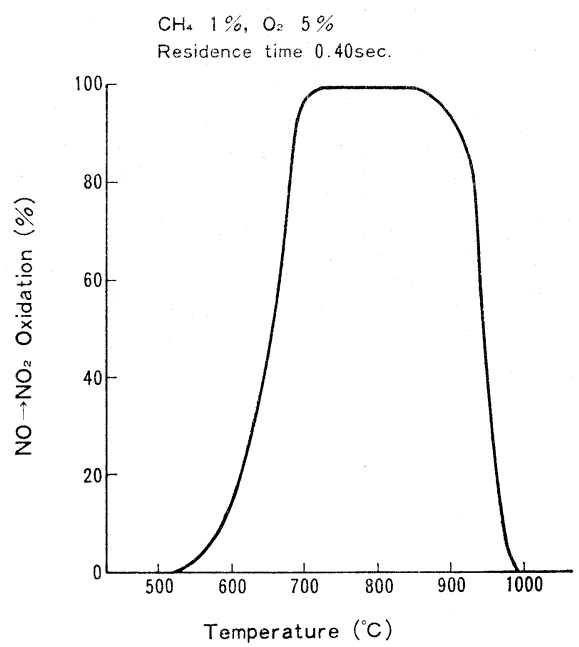

Fig. 11 NO oxidation at $\mathrm{CH}_{4}-\mathrm{O}_{2}-\mathrm{NO}$ sys. (calculated) 


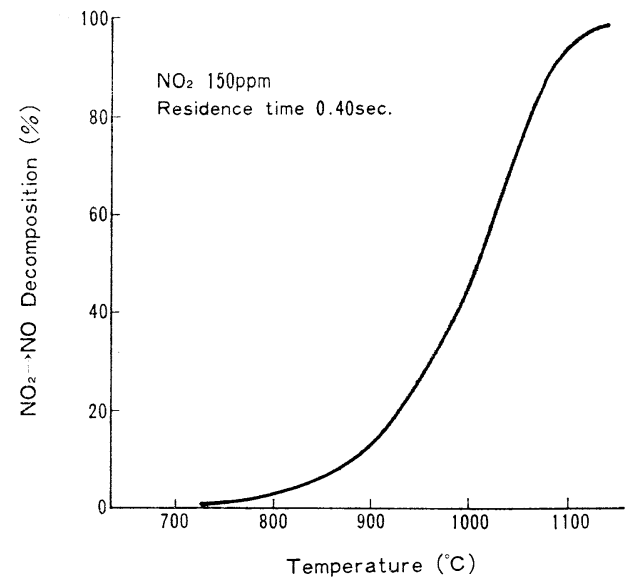

Fig. 12 Decomposition of $\mathrm{NO}_{2}$ (calculated)

系については，その関連する素反応の速度定数につい て, 現在でも議論があるものが多く, HCHO 㧊よび 前報 $\mathrm{CH}_{3} \mathrm{OH}$ の実験結果の説明に困難を生じた。ここ では，特に， HCHO-NO-O 2 系の反応に大き影響 をもつ21，33両式（反応式の付番は Table 1 と同一） の反応速度定数について検討した。

1) $\mathrm{HCHO}$ の分解反応

HCHO の分解反応については 現在も議論がなさ礼 て特り,

$$
\begin{aligned}
& \text { i) } \mathrm{HCHO}+\mathrm{M} \rightarrow \mathrm{H}_{2}+\mathrm{CO}+\mathrm{M} \\
& \left\{\begin{array}{l}
\mathrm{ka}=2.1 \times 10^{15} \exp (-35,000 / \mathrm{RT})^{6)} \mathrm{cm}^{3} / \mathrm{mol} \cdot \mathrm{sec} \\
\mathrm{k}^{\prime} \mathrm{a}=2.1 \times 10^{16} \exp (-35,000 / \mathrm{RT})^{7)}
\end{array}\right. \\
& \text { ii) } \mathrm{HCHO}+\mathrm{M} \rightarrow \mathrm{H}+\mathrm{CHO}+\mathrm{M} \\
& \left\{\begin{array}{l}
\mathrm{k}_{\mathrm{b}}=1.0 \times 10^{14} \exp (-36,760 / \mathrm{RT})^{8)} \\
\mathrm{k}^{\prime}{ }_{\mathrm{b}}=5.01 \times 10^{16} \exp (-72,000 / \mathrm{RT})^{9)}
\end{array}\right.
\end{aligned}
$$

なぞの反応および反応速度定数が与えられている。し かも，いずれも $1,500^{\circ} \mathrm{K}$ 以上の燃尭域を対象としてお り，本試験のような $800^{\circ} \mathrm{K} \sim 1,200^{\circ} \mathrm{K}$ にそのまま㗅用 できるか否かについては検討を要する。

さて, 本モデルで反応として上記 i ), 反応速度定 数として $\mathrm{k}_{\mathrm{a}}$ または $\mathrm{k}_{\mathrm{a}}$ の夕を用いると, $\mathrm{HCHO}-\mathrm{O}_{2-}$ $\mathrm{NO}$ 系では, $\mathrm{HCHO}$ はその汪とんどが, $\mathrm{CO}, \mathrm{H}_{2}$ とな って安定してしまい, 従って $\mathrm{NO}_{2}$ の生成はごく微量

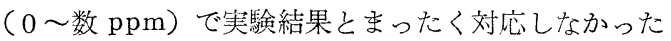
（また， $\mathrm{CH}_{3} \mathrm{OH}$ の場合も実験值より酸化率が低くな る)。また，HCHO の分解反応として上記 i ）と ii） の双方を考慮し，かつ，双方に種々の反応速度定数を 与兄て計算した結果, 反応 i ) の速度定数を大きく見 積ると, $\mathrm{NO}$ の $\mathrm{NO}_{2}$ への酸化率が低下し, 酸化率の ピークは低温側へ移行すること, 反応 ii ) の速度定数を
大きく見積った場合には HCHO の分解が促進され, $\mathrm{NO}$ の $\mathrm{NO}_{2}$ への酸化率のピークは低温側へ移行する が，ピークの酸化率は高くなることが判った。

2) $\mathrm{CHO}+\mathrm{O}_{2} \rightarrow \mathrm{CO}+\mathrm{HO}_{2}$ (33式) 反応

本反応は NOV対して最終的に酸化作用を及ぼす $\mathrm{HO}_{2}$ (70式)の生成反応であり重要であるが，これに ついては,

$$
\begin{aligned}
\mathrm{k}_{\mathrm{c}} & =1.00 \times 10^{14} \exp (-6,800 / \mathrm{RT})^{10)} \\
\mathrm{k}^{\prime}{ }_{\mathrm{c}} & =4.95 \times 10^{13} \exp (-1,590 / \mathrm{RT})^{4)}
\end{aligned}
$$

などの值がある。モデル計算の結果では，33式反応の 速度を低く見積ることにより，HCHO 分解開始温度 が下り，分解が促進される（かつピークの NO 值は 低下寸る）から本反応は $\mathrm{HCHO}$ 分解の連鎖反応の阻 害反応である。すなわ方, HCHO-NO-O 2 系での NO の $\mathrm{NO}_{2}$ への酸化反応の主要経路は,

$$
\begin{aligned}
& \mathrm{HCHO}+\mathrm{M} \rightarrow \mathrm{CHO}+\mathrm{H}+\mathrm{M} \\
& \mathrm{CHO}+\mathrm{O}_{2} \rightarrow \mathrm{HO}_{2}+\mathrm{CO} \\
& \mathrm{HO}_{2}+\mathrm{NO} \rightarrow \mathrm{NO}_{2}+\mathrm{OH} \\
& \mathrm{NO}_{2}+\mathrm{H} \rightarrow \mathrm{NO}+\mathrm{OH}
\end{aligned}
$$

之考えられるが，33式は他の HCHO 分解反応（29 32式）を阻害し，結果的に連鎖反応の進行を抑止する ものと思われる。

以上の 1)，2）を考慮した結果，実験結果と良好に 対応する反応扣よび反応速度定数として HCHO の分 解反応としては，上記 ii ）反応拈よび $\mathrm{k}_{\mathrm{b}} \mathrm{b}_{\mathrm{b}}$ の夕を採用 ᄂ, $\mathrm{CHO}+\mathrm{O}_{2} \rightarrow \mathrm{CO}+\mathrm{HO}_{2}$ 反応については $\mathrm{k}_{\mathrm{c}}^{\prime}$ 式を 選んだのである。

それぞれの添加物についてモデル計算から得られた 知見は次の通りである。

1) $\mathrm{H}_{2}$

$\mathrm{H}_{2}$ の場合には他の $\mathrm{HCHO}, \mathrm{H}_{2} \mathrm{O}_{2}, \mathrm{CH}_{3} \mathrm{OH}, \mathrm{CH}_{4}$ と比較して $\mathrm{NO}_{2}$ 酸化のために最適な温度域が低い。 これは高温度では, 他の添加物に比し, $\mathrm{H}_{2}$ の酸化反 応に上る $\mathrm{H}$ の生成量が大きく, $\mathrm{NO}_{2}+\mathrm{H} \rightarrow \mathrm{NO}+\mathrm{OH}$ (69式) の $\mathrm{NO}_{2}$ 再分解反応が増大するためと思われ る。

Fig.13 飞 $\mathrm{H}_{2}-\mathrm{O}_{2}-\mathrm{NO}$ 系の各成分の経時変化（計算 結果例）を示す。

2) $\mathrm{H}_{2} \mathrm{O}_{2}$

$\mathrm{H}_{2} \mathrm{O}_{2}$ では他の添加物と異なり, $\mathrm{O}_{2}$ の不在下でも $\mathrm{NO}$ は $\mathrm{NO}_{2}$ 酒化されるから本検討範囲では $\mathrm{O}_{2}$ は まったく反応関与していないと考光られる。すなわ ち，他添加剤においては $\mathrm{O}_{2}$ との反応での反応中間体 が $\mathrm{NO}_{2}$ の生成に寄与寸るのに対し, $\mathrm{H}_{2} \mathrm{O}_{2}$ の場合に は $\mathrm{NO}$ と $\mathrm{H}_{2} \mathrm{O}_{2}$ との直接反応（ただし，最終的には 


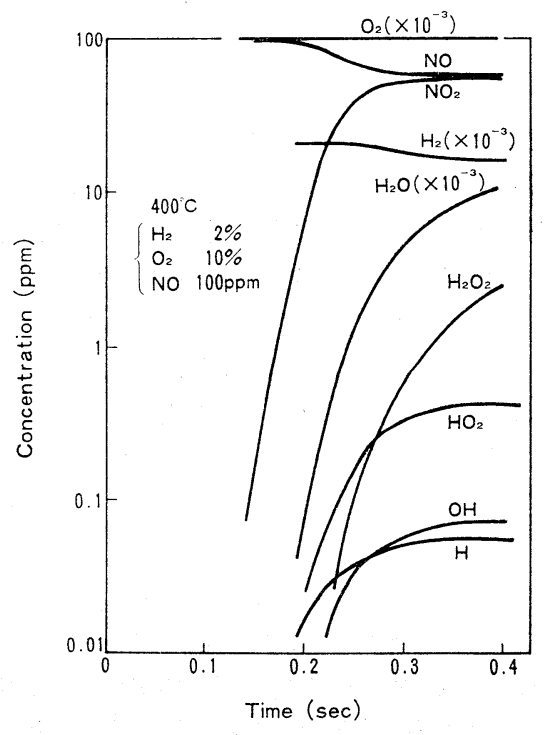

Fig. 13 Species concentration profiles at $\mathrm{H}_{2}-\mathrm{O}_{2}-\mathrm{NO}$ sys. (calculated)

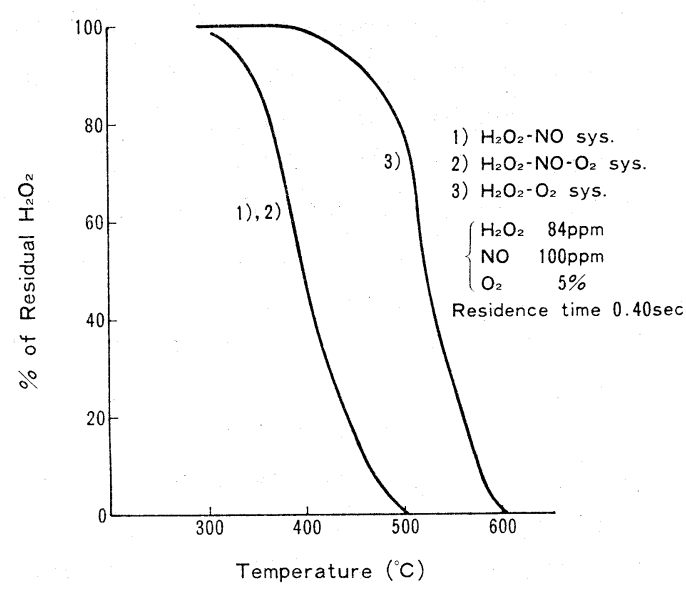

Fig. 14 Decomposition of $\mathrm{H}_{2} \mathrm{O}_{2}$ (calculated)

$\mathrm{HO}_{2}$ と $\mathrm{NO}$ の反応と思われる）により $\mathrm{NO}_{2}$ が生成 する。また NO との反応のため, NO が存在しない 場合より $\mathrm{H}_{2} \mathrm{O}_{2}$ の分解は促進される (Fig.14)。Fig.15 飞 $\mathrm{H}_{2} \mathrm{O}_{2}-\mathrm{O}_{2}-\mathrm{NO}$ 系反応での各成分の経時変化 (計算 結果例)を示す。

\section{3) $\mathrm{HCHO}$}

HCHO の場合には，NO 酸化特性怯酸素濃度，温 度について前報の $\mathrm{CH}_{3} \mathrm{OH}$ と類似した依存性を示す。 酸素濃度が低いほど低温側に $\mathrm{NO}_{2}$ 酸化率のピークが 㐫り，この傾向は実験結果 (Fig.10) と同一であるが， モデル計算では低温領域 $\left(550 \sim 600^{\circ} \mathrm{C}\right)$ で低 $\mathrm{O}_{2}$ 濃度

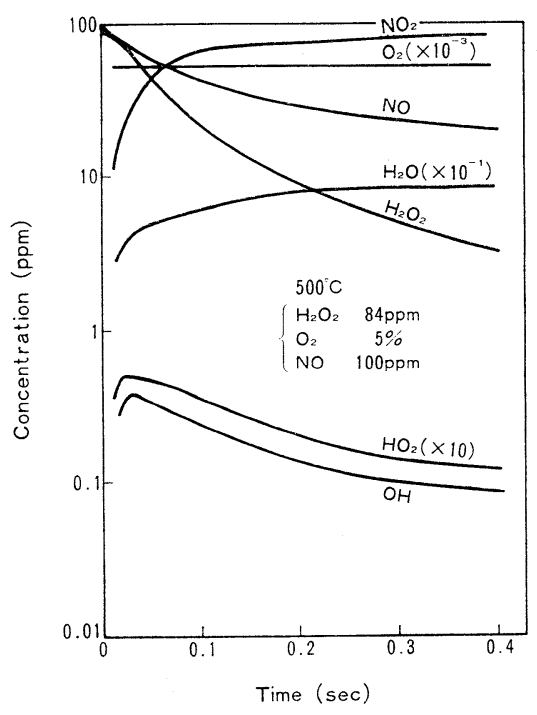

Fig. 15 Species concentration profiles at $\mathrm{H}_{2} \mathrm{O}_{2}-\mathrm{O}_{2}-\mathrm{NO}$ sys. (calculated)

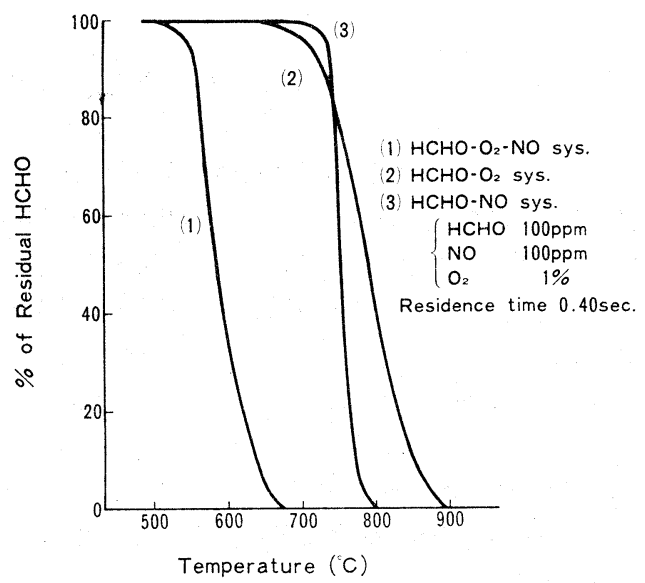

Fig. 16 Decomposition of HCHO (calculated)

の方が，高い酸化率を示す部分が生じている。また， $\mathrm{O}_{2}$ が存在しないと $\mathrm{NO}_{2}$ は生成しない。Fig.16亿 HC HO の分解特性, Fig.17 亿各成分の経時変化(計算結 果例) を示す。Fig.16から NOの HCHO の分解反応 に対する促進作用が理解されよう。

4) $\mathrm{CH}_{4}$

$\mathrm{CH}_{4}$ の場合には, 実験では $\mathrm{NO}_{2}$ 以外の $\mathrm{N}$ 生成物が生 じており，これらを考慮していない本モデル計算では 解析は不可能であるが，本モデルのままでは600～650 ${ }^{\circ} \mathrm{C}$ にピークがあり, $\mathrm{NO} \rightarrow \mathrm{NO}_{2}$ 酸化率は実験值より高 い。今後，たとえば， $\mathrm{HCN}$ などを経由する N2 の生 成等をも考慮する必要があろう。 


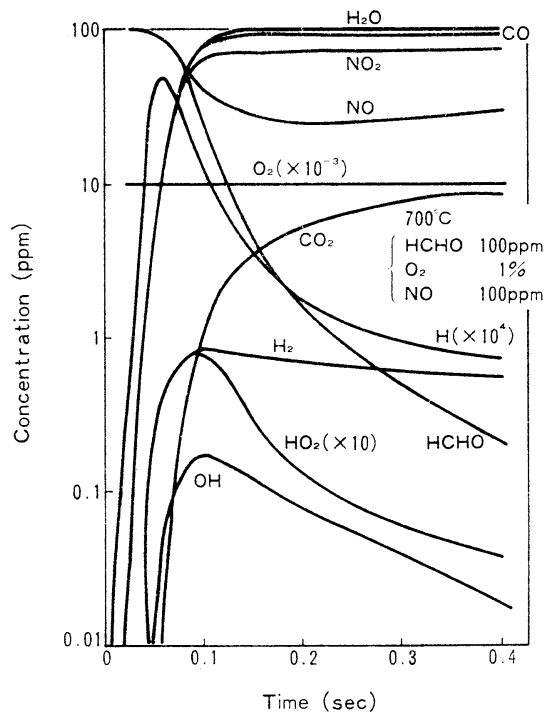

Fig. 17 Species concentration profiles at $\mathrm{HCHO}-\mathrm{O}_{2}-\mathrm{NO}$ sys. (calculated)

5) $\mathrm{NO}_{2}$

$\mathrm{NO}_{2}$ のみの分解については, モデル計算と突験值 はほぼ一致している。

また，上記 1）～4）の添加物のいずれの場合も， 前報 $\mathrm{CH}_{3} \mathrm{OH}$ の場合と同様に, 反応中間体である $\mathrm{HO}_{2}$ の存在が $\mathrm{NO}_{2}$ 生成に重要であり, 下記反応を考慮し ないと，計算結果はいずれの添加物の場合も， $\mathrm{NO}_{2}$ 生 成量は微少量となる。

$\mathrm{HO}_{2}+\mathrm{NO} \rightarrow \mathrm{NO}_{2}+\mathrm{OH}$

(70式)

\section{5. 結言}

$\mathrm{O}_{2}$ 存在下, $\mathrm{H}_{2}, \mathrm{H}_{2} \mathrm{O}_{2}, \mathrm{HCHO}, \mathrm{CH}_{4}$ を添加剂とし た $\mathrm{NO}$ の $\mathrm{NO}_{2}$ への酸化反応に着目した試験を実施 し, 次の知見を得た。

1) これらの添加剤は, すべて, $400 \sim 800^{\circ} \mathrm{C}, \mathrm{O}_{2}$ 存
在下において $\mathrm{NO}$ を $\mathrm{NO}_{2}$ に酸化する作用を有する （ただし， $\mathrm{H}_{2} \mathrm{O}_{2}$ のみは $\mathrm{O}_{2}$ の存在は不要である)。

2) $\mathrm{H}_{2}, \mathrm{CH}_{4}$ は $\mathrm{NO}$ の数十倍以上のモル量が必要 であるのに比し, $\mathrm{H}_{2} \mathrm{O}_{2}, \mathrm{HCHO}$ は当量モル程度の存 在で NOに作用する。

3) $\mathrm{NO}$ から $\mathrm{NO}_{2}$ への酸化反応には中間体として $\mathrm{HO}_{2}$ の存在が重要であり, 22 種の化学種, 70 素反応 群を用いた反応モデルにより，これら添加剤の反応特 性を矛盾なく説明することができた。

なお，本試験では生成ガス中の成分としておもに $\mathrm{NO}, \mathrm{NO}_{2}$ のみを計測したが，今後，他の成分をも追 跡計測し，モデルの検証を行っていくことが必要と考 える。

\section{文献}

1）村上ら, 燃協誌，61，276 (1982)

2）森ら，“燃焼反応に伴ら砖境污染物質の挙動研究 分科会成果報告書”日本機械学会(昭和50年)

3) J.D. Allen, Combustion and Flame, 24, 133 (1975)

4）たとえば，特開昭52-38460，52-50222，54-37095， 52-42461，52-85967，52-91776，53-33975 など

5）含谷, 然焼研究, 44, 16 (1977)

6）宮内, 然烸研究，44, 1 (1977)

7) J. Peeters, et al., Forteenth Symposium (International) on Combustion, 133, The Combustion Institute (1973)

8) C. T. Bowman, Fifteenth Symposium (International) on Combustion, 869, The Combustion Institute (1975)

9) H. G. Schecker, et al., Ber. Bunsenges. Phys. Chem., 73, 521 (1969)

10) H. Cremer, Chemie-Ing-Teh., 44, 8 (1972) 


\section{Oxidation of $\mathrm{NO}$ to $\mathrm{NO}_{2}$ in the Flue Gas (II)}

-Oxidation by Addition of $\mathrm{H}_{2}, \mathrm{H}_{2} \mathrm{O}_{2}, \mathrm{HCHO}, \mathrm{CH}_{4}^{--}$

Nobuaki Murakami, Jun IzUmi, Seiichi SHIRAKAwa

(Mitsubishi Heavy Industries, Ltd.)

SYNOPSIS : - In this report, the reaction characteristics of $\mathrm{O}_{2}-\mathrm{NO}-\mathrm{H}_{2}, \mathrm{H}_{2} \mathrm{O}_{2}$, $\mathrm{HCHO}, \mathrm{CH}_{4}$ systems were investigated, expecting the oxidation of $\mathrm{NO}$ to $\mathrm{NO}_{2}$.

Main results were summerized as follows.

1) These chemicals $\left(\mathrm{H}_{2}, \mathrm{H}_{2} \mathrm{O}_{2}, \mathrm{HCHO}, \mathrm{CH}_{4}\right)$ have the effect of oxidizing $\mathrm{NO}$ to $\mathrm{NO}_{2}$ at $400 \sim 800^{\circ} \mathrm{C}$ in the presence of $\mathrm{O}_{2}$ (only $\mathrm{H}_{2} \mathrm{O}_{2}$ don't need the presence of $\mathrm{O}_{2}$ )

2) In the case of $\mathrm{H}_{2} \mathrm{O}_{2}$ and $\mathrm{HCHO}$, oxidation of $\mathrm{NO}$ to $\mathrm{NO}_{2}$ was occured at [M]/ $[N O] \gtrsim 1([\mathrm{M}] /[\mathrm{NO}]$; molar ratio of added chemicals to $\mathrm{NO})$, but in the case of $\mathrm{H}_{2}$ and $\mathrm{CH}_{4}$ higher value of $[\mathrm{M}] /[\mathrm{NO}]$ was needed.

3) The important role of $\mathrm{HO}_{2}$ radicals in oxidation of $\mathrm{NO}$ to $\mathrm{NO}_{2}$ was recognized, from the kinetic model calculation including 22 species and 70 elementary reactions. 